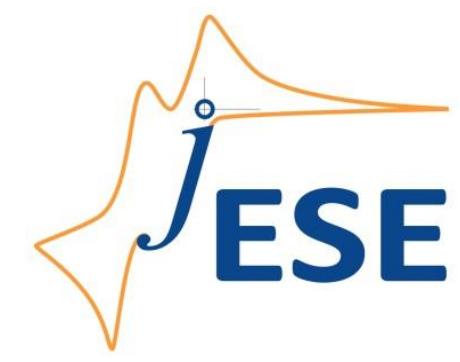

Open Access: ISSN 1847-9286

www.jESE-online.org

Original scientific paper

\title{
Electrokinetic removal of heavy metals from soil
}

\author{
Puvvadi Venkata Sivapullaiah ${ }^{凶}$, Bangalore Sriakantappa Nagendra Prakash* and \\ Belagumba Nagahanumantharao Suma* \\ Department of Civil Engineering, Indian Institute of Science, Bangalore - 560 012, India \\ *Department of Civil Engineering, UVCE, Jnana Bharathi Campus, Bangalore University, \\ Bangalore -560 087, India
}

E-mail: siva@civil.iisc.ernet.in, Phone: +91-80-22932672; Fax: +91-80-23600404

Received: April 3, 2014; Revised: May 29, 2014; Published: March 15, 2015

\begin{abstract}
Removal of heavy metal ions from soils by electrokinetic treatment has several advantages. The extent of removal, however, is both soil specific and ion specific. The conditions to be maintained have to be established based on laboratory studies. With a view to maximize the removal of metal ions the trends of removal of heavy metal ions such as iron, nickel and cadmium form a natural Indian kaolinitic red earth during different conditions maintained in the electrokinetic extraction process are studied. A laboratory electrokinetic extraction apparatus was assembled for this purpose. Attempts are also made to elucidate the mechanism of removal of the metal ions from soil. The composition of the flushing fluid, voltage and duration of extraction are varied. While dilute acetic acid has been used to neutralize the alkalinity that develops at the cathode, EDTA solution has been used to desorb heavy metals from clay surface. Generally the extent of removal was proportional to the osmotic flow. Nickel and Cadmium are more effectively removed than iron. The percentage removal of $\mathrm{Ni}$ is generally proportional to the osmotic flow but shows sensitivity to the $\mathrm{pH}$ of the system. There is an optimum voltage for removal of metal ions from soil. The removal of iron was negligible under different conditions studied.
\end{abstract}

\section{Keywords}

Electric; Clays; Metal ions; Removal; Sorption

\section{Introduction}

Heavy metal toxicity occurs far more often and people are exposed to toxic metals on a day-today basis in our environment. Military activities are one of the primary contributors to metals contaminated soil problems. Military operations such as small arms training, electroplating and metal finishing operations, explosive and propellant manufacturing and use, and the use of lead based paint at military facilities, have resulted in vast tracts of land being contaminated with 
metals. Whether heavy metal poisoning comes either from these or from cooking utensils, deodorants, pesticides, etc., all have a devastating effect on the human body. Both soils and ground water are often contaminated with heavy metals ions. The existing methods to removal of these metals, particularly from fine grained soils are not often successful or are not cost effective. Electrokinetic remediation has been used to remediate soil and ground water [1].

Electrokinetic remediation of soils offers several advantages over the other remediation methods that are in widespread use today. These include: (i) It is an in-situ process that is $50-90 \%$ less expensive than the currently available metals remediation technologies, such as soil washing, pump and treat, and excavation, which are ex-situ methods; (ii) It is extremely effective in finegrained low permeability soils where other techniques, such as pump and treat, are not feasible. This is due to the fact that the contaminants are transported under charged electrical fields and not hydraulic gradients. (iii) It is suitable for heterogeneous materials such as soils and pressuredriven flushing processes invariably channel the fluid through the largest size pores, leaving the smaller ones nearly untouched. In low-permeability soils, the electro-osmotically driven flow is insensitive to pore size, which allows a rather uniform flow distribution and is applicable equally to coarse and fine-grained soils.

\section{Electrokinetic extraction of contaminants}

Electrokinetic remediation is an in-situ process in which an electrical field is created in a soil matrix by applying a low-voltage direct current (DC) to electrodes placed in the soil. As a result of the application of this electric field, heavy metal contaminants may be mobilized, concentrated at the electrodes, and extracted from the soil.

The mass transport processes induced during electrokinetic treatment are primarily electroosmosis of water, ion-migration and electrophoretic transport of colloids. The rate and efficacy of these processes are often found to depend upon the mineral and chemical composition of the soil and soil water, and the type, age, distribution, and concentration of the contamination. An excellent review of electrokinetic flow processes in soils is given by Yeung [2].

For practical purposes, electro-osmotic fluid volume flow rate is described as analogous to Darcy's law.

$$
Q=k_{\mathrm{e}} l_{\mathrm{e}} A
$$

Where $Q=$ fluid volume flow rate $\mathrm{m}^{3} / \mathrm{s}$;

$k_{\mathrm{e}}=$ coefficient of electro-osmotic conductivity, $\mathrm{m}^{2} / \mathrm{V} \mathrm{s}$

$l_{\mathrm{e}}=$ hydraulic gradient of electro-osmotic flow, $\mathrm{m}$

$A=$ total cross-sectional area perpendicular to the direction of fluid flow, $\mathrm{m}^{2}$.

The values of coefficient electroosmotic conductivity of different soils lie in the narrow range of $1 \times 10^{-9}$ to $1 \times 10^{-8} \mathrm{~m}^{2} / \mathrm{V}$. Therefore, an electric field is a much more effective force in driving fluid through fine-grained soils of low hydraulic conductivity than a hydraulic gradient. During an electrokinetic extraction process, the applied DC electric field can thus drive an effective electroosmotic advection of contaminants through the soil and/or inject enhancement agents into the contaminated soil.

Ionic migration or electromigration is the movement of charged chemical species relative to the movement of pore fluid. Anions (negatively charged ions) are moved towards the anode (positive electrode) and cations (positively charged ions) are moved towards the cathode (negative electrode). The alkali metals and alkali earth metals such as $\mathrm{Na}, \mathrm{K}, \mathrm{Cs}$ and $\mathrm{Sr}$, Ca tend to remain ionic under a wide range of $\mathrm{pH}$ and redox potential values. Therefore they are expected to 
electromigrate and be extracted from soil readily unless they become preferentially sorbed onto solid surfaces and clay interstices. Under ideal conditions, the predominant cation and its accompanying anion may be caused to separate efficiently by electromigration only, for which little or no electroosmotic water advection may be necessary. The ionic mobilities of ions in free dilute solutions, i.e., the velocities of the ions under the influence of a unit electric field, are in the range of $1 \times 10^{-8}$ to $1 \times 10^{-7} \mathrm{~m}^{2} / \mathrm{V}$.

Combining the mechanisms of electroosmotic advection and ionic migration results in the applicability of electrokinetic extraction. Past experience with electrochemical treatment of contaminated porous media has shown that the process is most effective when the transported substances are ionic; surface charged or in the form of small micelles with little drags resistance. The effect of ionic migration of anions may be diminished by that of electro osmotic advection. However the direction of electro-osmotic flow may reverse during a prolonged application of a DC electric field across fine-grained soils. The phenomenon of reverse electro-osmotic flow cannot be described by (1) and is not well understood. Most experimental results obtained to date indicate that ionic migration is the dominant.

\section{Factors governing electro-kinetic removal}

There are many practical aspects of the technology that needs to be considered carefully before the technology can be successfully implemented in the field.

\section{Soil type}

This technology can be successfully applied to clayey to fine sandy soils. It appears that soil type does not pose any significant limitation on the technology. However, contaminant transport rates and efficiencies depend heavily on soil type and environmental variables. Soils of high water content, high degree of saturation, and low activity provide the most favorable conditions for transport of contaminants by electro-osmotic advection and ionic migration. However, soils of high activity, such as Illite, montmorillonite, and impure kaolinite, exhibit high acid/base buffer capacity and require excessive acid and/or enhancement agents to disrobe and solubilize contaminants sorbed on the soil particle surface before they can be transported through the subsurface and removed. Moreover the high sorbtive capacity of the clayey soil for contaminant would further aggravate the problem by retarding contaminant transport.

The effects of the soil mineralogy on removal of chromium from soils by electrokinetics were also investigated by [3]. Their results indicate that the presence of carbonate and hematite can adversely impact the process. Values of hydraulic conductivity in different types of soils within a heterogeneous deposit can vary many orders of magnitude. For a contaminated soil deposit containing interlayer of sand and clay, typical values of hydraulic conductivity of these strata are $1 \times 10^{-4}$ and $1 \times 10^{-8} \mathrm{~m} / \mathrm{s}$, respectively. However, the values of electric conductivity of these soils are still within the order of magnitude. As a result the electric field strengths in the different soil layers will be similar when the externally electric potential is applied across the deposit. As the coefficient of electro-osmotic conductivity is insensitive to soil type, the electro-osmotic fluid volume flow rates in different soil layers will thus be very similar.

Complete removal of those metals that possess complex aqueous and electrochemistry and tendency for speciation and forming hydroxide complexes is particularly difficult under variable $\mathrm{pH}$ and redox conditions. The technique has been successful to remove $>90 \%$ of heavy metals (arsenic, cadmium, cobalt, chromium, copper, mercury, nickel, manganese, molybdenum, lead, antimony, and zinc) from clay, peat and argillaceous sand [4]; to remove spiked lead from kaolinite 
$[5,6]$; to remove $85-95 \%$ of the original concentrations of cadmium, cobalt, nickel, and strontium from laboratory samples prepared from Georgia kaolinite, Na-montmorillonite, and sandmontmorillonite mixture [7]; to remove cadmium from saturated kaolinite [8].

\section{Contaminant type and concentrations}

Available experimental data indicate that removal of heavy metals, radio-nuclides, and selected organics by electrokinetics is feasible. Focus is given for the removal of metals in this study. It is anticipated that pollutant, such as $\mathrm{PbO}$, may dissolve and advance through the soil. The process helps in migration of different contaminants in the soil simultaneously. Therefore, the type of contaminant does not pose a significant limitation on the technology, provided the contaminant does not exist in the sorbed phase on the soil particle surface or as precipitates in the soil pore. However a high concentration of ions in the pore fluid will increase the electrical conductivity of soil and thus reduce the efficiency of electro-osmotic fluid flow. More the strength of the electric field applied may have to be reduced to prevent excessive power consumption and heat generation during the process. Nonetheless the concentration of the contaminant does not pose any insurmountable hurdle to the application of the process.

\section{pH gradient across the electrokinetic cell}

An electric field causes electrolysis of water and the $\mathrm{pH}$ value will drop at the anode and it will increase at the cathode as the produced ions by electrolysis move corresponding to their charge to the electrode of opposite polarity, causing a $\mathrm{pH}$ gradient in the soil. When an electric field is applied to wet soil, the soil $\mathrm{pH}$ undergoes transient and spatial variation due to decomposition of water, which in turn affect soil surface properties such as cation exchange capacity, ion (cation and anion) adsorption capacity, and magnitude and sign of the $\xi$ potential. Similarly, the electric gradient does not remain constant in time and space due to the changing resistivity and redistribution of the charges in the soil; and oxidation/reduction state of the soil, contaminants and also the aqueous solution near the electrodes. Rødsand et al. [9] demonstrated the use of acetic acid to depolarize the cathode reaction and an ion-selective membrane to halt the hydroxyl migrating from the cathode into the soil and enhances electrokinetic extraction of lead while the membrane extraction technique does not enhance the technique as expected.

\section{Voltage and current levels}

The electric current densities used in most studies are in the order of a few tens of $\mathrm{mA} / \mathrm{cm}^{2}$. Although a high current intensity can generate more acid and increase the rate of transport to facilitate the contaminant removal process, it increases power consumption tremendously, as power consumption is directly proportional to the square of electric current. An electric current density in the range of $1-10 \mathrm{~A} / \mathrm{m}^{2}$ has been demonstrated to be the most efficient for the process. However appropriate selection of electric current density and electric field strength depends on the electrochemical properties of the soil to be treated, in particular the electric conductivity. The higher the electric conductivity of the soil, higher will be the required electric current density needed to maintain the required electric field strength. Electric field strength of the order of $50 \mathrm{~V} / \mathrm{m}$ can be used as an initial estimate for the process. An optimum electric current density or electric field strength should be selected based on soil properties, electrode spacing, and time requirements of the process. 


\section{Effluent chemistry and enhancement scheme}

Contaminants can exist in different chemical forms in the subsurface depending on environmental conditions. They can exist as solid precipitates, dissolved solutes in the soil pore fluid and/or bonded species on organic matters in the soil. Among these different forms, only dissolved solutes are mobile and removable by electrokinetic extraction and many other remediation technologies. Transformation processes of the contaminant between different chemical forms are contaminant specific, reversible, and dependent on environmental conditions. Nonetheless, most contaminants can be transformed to their dissolved forms. The acidic environment generated at the anode aids in de-sorption and dissolution of metal contaminants from the soil particle surface. However, the basic environment generated at the cathode can hinder the removal of metal contaminants from the soil. In some cases it is necessary to inject reagents into the soil to enhance solubility and transport of metal contaminants. In an acid environment, some metal ions exist as anionic complexes. Both chemical forms are soluble and thus can be extracted from the soil by the process.

It is thus clear that the success of an electrokinetic extraction of contaminants from polluted soils depends on the physical and chemical properties of the soil, the contaminant, and the operating parameters of the extraction system. It is necessary to understand the relative influences of various mechanisms such as osmotic flow induced and the applicability of various enhancement schemes and conditions to be maintained during extraction.

\section{Materials and methods}

Soil used

Red earth used in this study was obtained from Indian Institute of Science, campus Bangalore. The soil was collected by open excavation from a depth of one meter from the natural ground. The soil was dried and passed the IS sieve size of $425 \mu \mathrm{m}$. The soil so obtained has clay content of $35 \%$. The clay content consisted predominantly of kaolinitic mineral. Properties of red earth are summarized in Table 1.

Table 1. Properties of Red Earth

\begin{tabular}{cc}
\hline Property & Red Earth \\
\hline Specific gravity & 2.73 \\
\hline Liquid limit, \% & 34.9 \\
\hline Plastic limit, \% & 17.7 \\
\hline Shrinkage limit, \% & 13.6 \\
\hline Max dry density, $\mathrm{g} / \mathrm{cm}^{3}$ & 1.79 \\
\hline Optimum moisture content, \% & 16.23 \\
\hline
\end{tabular}

\section{Preparations of metal ion solutions}

The chemicals, cadmium acetate $\left(\left(\mathrm{CH}_{3} \mathrm{COO}\right)_{2} \mathrm{Cd} \cdot 2 \mathrm{H}_{2} \mathrm{O}\right)$, nickel nitrate $\left(\mathrm{Ni}\left(\mathrm{NO}_{3}\right)_{2} \times 6 \mathrm{H}_{2} \mathrm{O}\right)$, ferric chloride $\left(\mathrm{FeCl}_{3}\right)$, acetic acid $\left(\mathrm{CH}_{3} \mathrm{COOH}\right)$ solution, hydrochloric acid $(\mathrm{HCl})$, used in this study. All these solution were prepared by adding required quantity of chemicals in deionised water. Standard $100 \mathrm{ppm}$ solutions of cadmium, nickel and iron were prepared by dissolving $2.372 \mathrm{~g}$, $4.955 \mathrm{~g}$ and $2.904 \mathrm{~g}$ respectively in distilled water and make it to $1000 \mathrm{ml}$. The solutions were 
acidified with a drop of $\mathrm{HCl}$. The concentrations of the collected fluid were measured using Atomic Absorption Spectrophotometer after standardization.

\section{Laboratory electrokinetic extraction cell}

As the experimental apparatus required for this study program was not readily available in India from conventional geotechnical testing equipment, a new apparatus designed, fabricated and assembled at the Geotechnical Laboratory, Department of Civil Engineering. Indian Institute of Science, Bangalore, India has been used.

The Electrokinetic cell was fabricated using nylon material for the body, which is a nonconductor of electricity, corrosive resistant, not affected by acid or alkali. The electrokinetic cell consists of two end caps and a specimen cylinder made up of nylon. The test sample was $80 \mathrm{~mm}$ in diameter and $300 \mathrm{~mm}$ long. Ten electrical measurement nodes have been installed on the specimen cylinder at $25 \mathrm{~mm}$ intervals so that the electrical voltage distribution along the sample can be monitored continuously during the test. The end caps house the graphite plate electrodes, inflow and outflow tubings. As porous graphite is extremely expensive and fabrication of porous graphite electrodes is very labor intensive, normal grade graphite plates were used in this study. Holes of $1 \mathrm{~mm}$ diameter were drilled through the graphite plate electrode to facilitate water transport during electro-osmosis. Details of electrokinetic cell are shown in Fig. 1 The required electrical circuit has been designed, connected and assembled. The circuit is designed to facilitate future automation of the experiment by means of computerized data acquisition system. Provision has been made to pass water through the soil compacted in the cell.

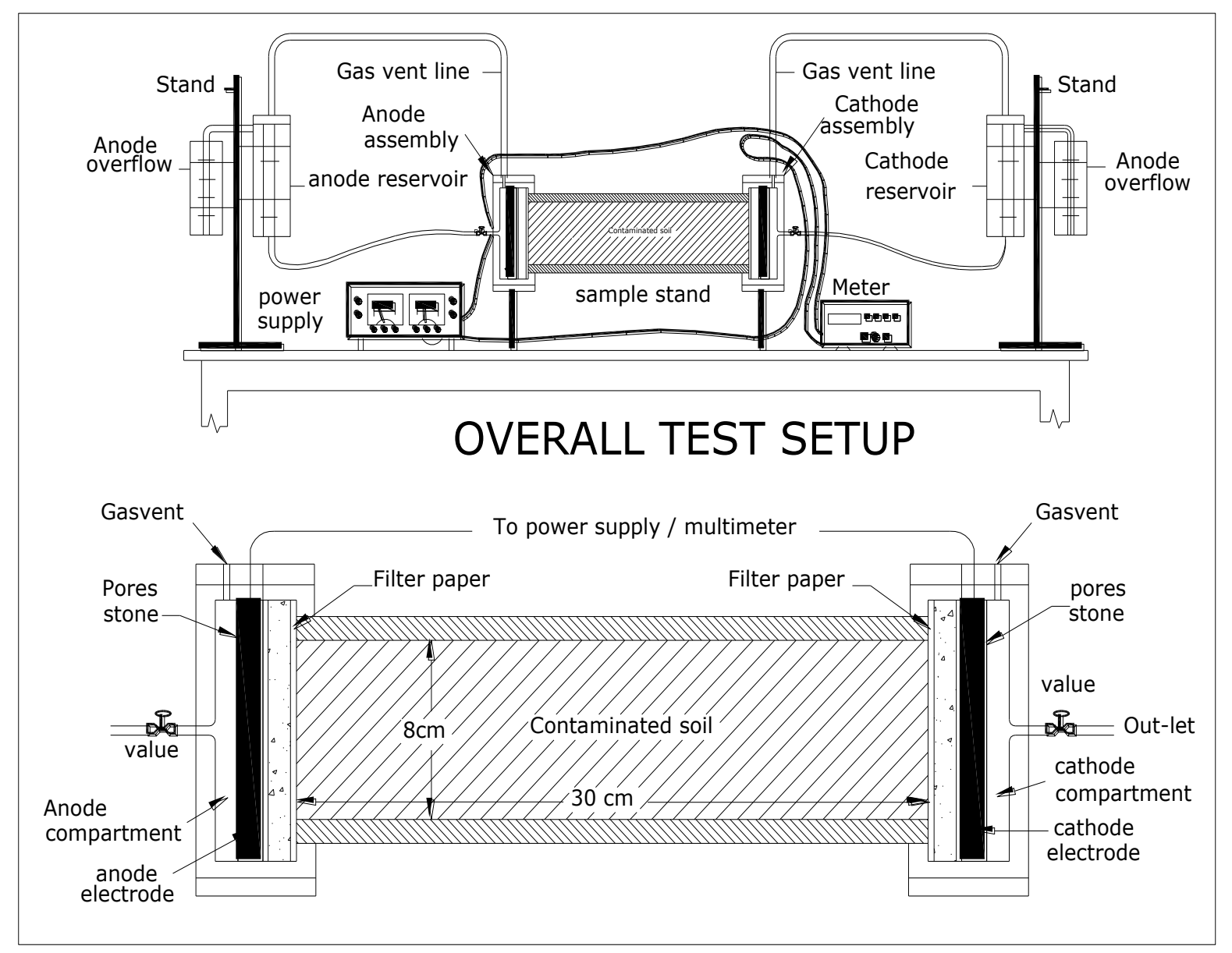

Fig. 1. Electrokinetic extraction apparatus. 


\section{Electro-Kinetic Extraction}

The procedure involves the following sequence,

1. Sample preparation,

2. Variation of flow through red earth with and without contaminants during different phases of extraction,

3. Calculation of electro osmotic permeability, and

4. Estimation of percent removal of metal ions.

The oven dried soil samples were mixed with required amount of water so as to bring it to $110 \%$ of optimum moisture content (OMC) which is about $17.93 \%$. These samples were kept one day in the desiccators to get uniform moisture content. To prepare contaminated soils with cadmium, nickel and iron solutions of cadmium acetate, nickel nitrate and ferric chloride containing the required amount of chemicals to bring it to $250 \mathrm{mg} / \mathrm{kg}, 500 \mathrm{mg} / \mathrm{kg}$ and $1000 \mathrm{mg} / \mathrm{kg}$ of soil mass respectively have been added. The soil samples were then compacted in the cell to bring it to $110 \%$ of maximum dry density on wet of optimum on the compaction curve. The soil is divided into three equal parts by weight and then each part is emplaced into the specimen cylinder and compacted one by one using a screw jack to ensure uniform compaction for the entire specimen.

After compaction, the perforated electrodes were covered with the filter papers and the end caps were closed. Fluid in-let and out let tubes were connected to the cell. Initially, the soil specimen was saturated by maintaining a hydraulic head using self-compensating device and then the head removed. The electrodes were then connected to a constant voltage power supply through the sample and flow is measured at regular intervals. The inlet and outlet were kept at same level such that the hydraulic head difference between them was zero. Then a DC voltage was passed through the cell. The change in the flow, $\mathrm{pH}$ and electro osmotic permeability on application of the DC voltage in the soil with and without any contaminant has been studied. After studying the effect of higher voltage the effect of the addition of acetic acid in presence of DC current on the flow, $\mathrm{pH}$ and electro osmotic permeability have been studied. Electrokinetic treatment was continued for a specific amount of time. The concentration of the contaminants in the out flow at the cathode induced by electro osmosis was measured using atomic absorption spectrophotometer. The percent removal of contaminants has been calculated.

\section{Results and discussion}

Electro-kinetic extraction of $\mathrm{Cd}, \mathrm{Ni}$, and $\mathrm{Fe}$ (III) ions

The removal of metal ions by induced osmotic flow and ion migration has been studied. The effect of increased voltage on osmotic flow and ion migration has been studied. Attempt has been made to understand the utility of passing acetic acid to control pH and the role of EDTA to desorb and remove contaminant has been studied.

\section{Osmotic flow through soil with and without contaminant}

Decontamination of fine grained soil by soil washing is largely inhabited because of their low hydraulic conductivity. One of the important processes by which the decontamination of soils by electro kinetic extraction process is achieved by enhanced flow through fine grained soils on application of voltage across the soil by electro osmosis. Osmotic induces flow through soil even without hydraulic gradient. The extent of osmotic flow through the soil depends on several factors such as type of soil, voltage applied, the type and amount of contaminants present in the soil. The 
effect of increased voltage across the soil on osmotic flow of fluid through the soil without any contaminants and with known amount of contaminants have been studied

Application of voltage across the soil increases the $\mathrm{pH}$ at the cathode and decreases the $\mathrm{pH}$ at the anode due to electrolysis of water. Increase in the $\mathrm{OH}^{-}$ion concentration near the cathode causes high negative value of zeta potential. This in turn increases the flow. For soils containing heavy metal ions the increase in the $\mathrm{pH}$ at cathode precipitates ions as hydroxides and reduces the flow rate. The $\mathrm{pH}$ at which the ion starts precipitating varies from ion to ion. The effect of this process on the rate of flow through the soil containing different types and levels of contaminant has been monitored.

The efficiency of passage of dilute acetic acid solution during electro kinetic extraction test after noticing the reduction in flow rate in increasing the flow rate has been studied. Increased acidity causes the zeta potential to become less negative. Flow rates have been observed to decrease due to this. However as long as the concentration of ions in the solution is sufficient, electromigration continues even when electro-osmosis has declined. The effect of increase in the voltage while passing of acetic acid to flow rate is monitored.

Application of voltage $(5 \mathrm{~V})$ induced flow initially. Increase in voltage (10 V) improves flow by almost 30 times as shown in Fig. 2. Prolonged application with enhanced voltage $(20 \mathrm{~V})$ doesn't influence the flow, as it is almost 0 . Passing of acetic acid revives flow but the $\mathrm{pH}$ remains on the basic front, may be due to deposition of $\mathrm{OH}^{-}$ions at the cathode. Further increase in voltage (30 V) along with acetic acid compliments the flow marginally due to neutralization of $\mathrm{OH}^{-}$ions at cathode. Increase in the voltage to $45 \mathrm{~V}$ along with acetic acid further enhances the flow considerably and observed to be the maximum during the monitor. However, prolonged application of higher voltage doesn't improve the flow any further, due to increase in $\mathrm{pH}$ at the cathode as in Fig. 3.

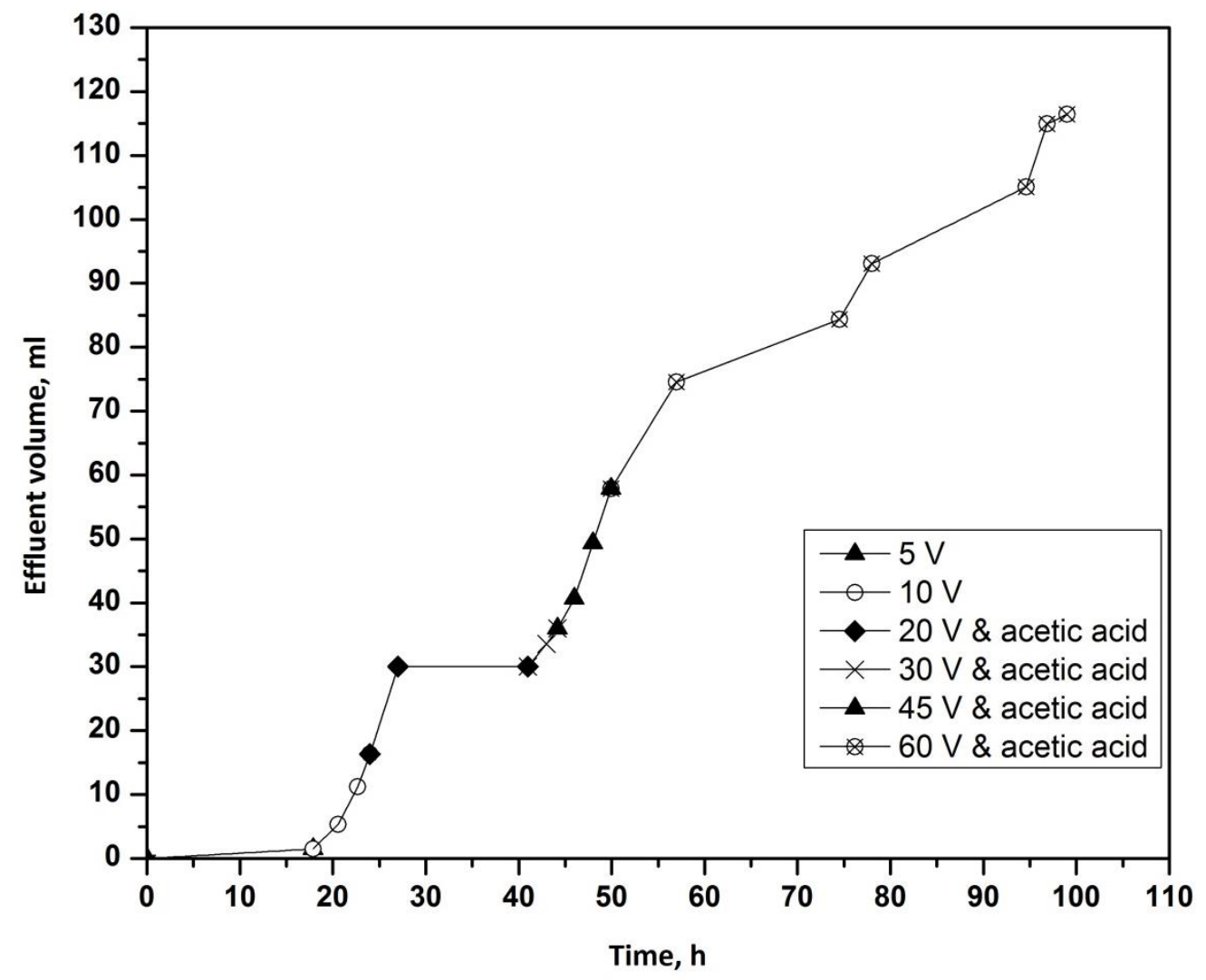

Fig. 2. Electrokinetic flow through uncontaminated soil 


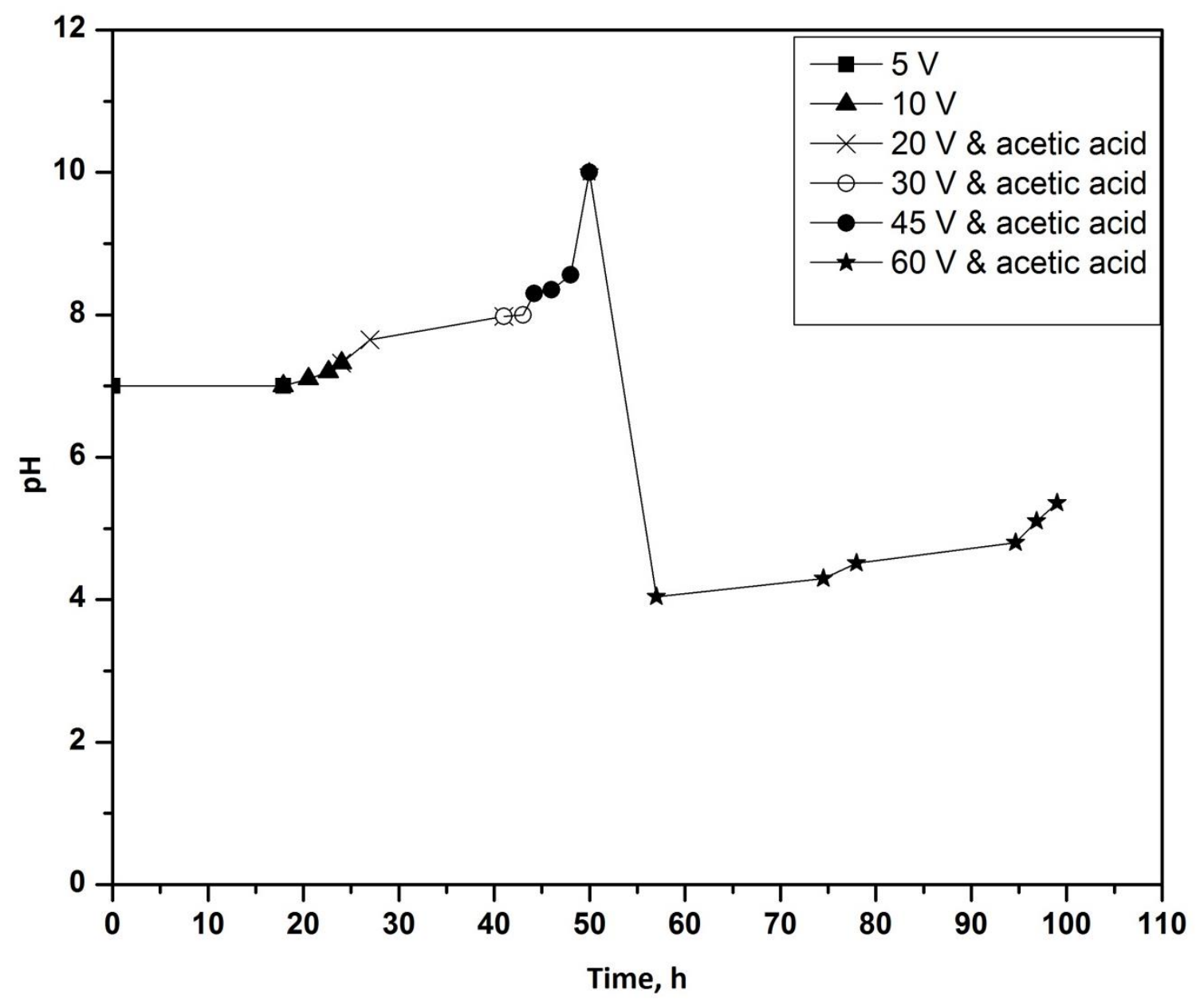

Fig. 3. Variation of $\mathrm{pH}$ of the effluent from uncontaminated soil

Based on the osmotic flow generated, the osmotic permeability of the soil has been calculated. The electro osmotic permeability of red earth without contaminant is in the range of $2.78 \pm 10^{-6}$ to $4.0 \times 10^{-5} \mathrm{~cm}^{2} / \mathrm{V}$ as shown in Fig. 4. At $5 \mathrm{~V}$ electro osmotic permeability was $2.78 \times 10^{-6} \mathrm{~cm}^{2} / \mathrm{V}$. Increase in the voltage to $10 \mathrm{~V}$ enhances electro osmotic permeability to $4.0 \times 10^{-5} \mathrm{~cm}^{2} / \mathrm{V}$ s being the maximum rate of flow. Increase in voltage to $20 \mathrm{~V}$ reduced electro osmotic permeability. Further increase in voltage with acetic acid revived electro osmotic permeability to $1.33 \times 10^{-5} \mathrm{~cm}^{2} / \mathrm{V}$ s. However increase in voltage further (60 V) and prolong application reduced electro osmotic permeability as shown in Fig. 4. Maximum electro osmotic permeability of red earth without contaminant is about $4.0 \times 10^{-5} \mathrm{~cm}^{2} / \mathrm{V} \mathrm{s}$ and is observed at $0.33 \mathrm{~V} / \mathrm{cm}$.

Effect of nickel ions on the osmotic flow through the soil

To measure the osmotic flow through the soil no hydraulic head was maintained and the flow did not occur. Significant increase in flow was observed on application of initial voltage (5 V) as shown in Fig. 5. Subsequent reduction in flow and increase in $\mathrm{pH}$ (Fig. 6), has been attributed to the precipitation of $\mathrm{OH}^{-}$ions at the cathode. Further enhancement of voltage (10 V) doesn't affect initially but increases the flow on addition of acetic acid at cathode side followed by the sudden reduction in $\mathrm{pH}$. Prolonged application of higher voltages (20,30, 45 and $60 \mathrm{~V})$ doesn't improve the flow any further, due to increase in $\mathrm{pH}$ at the cathode as shown in Fig 5. 


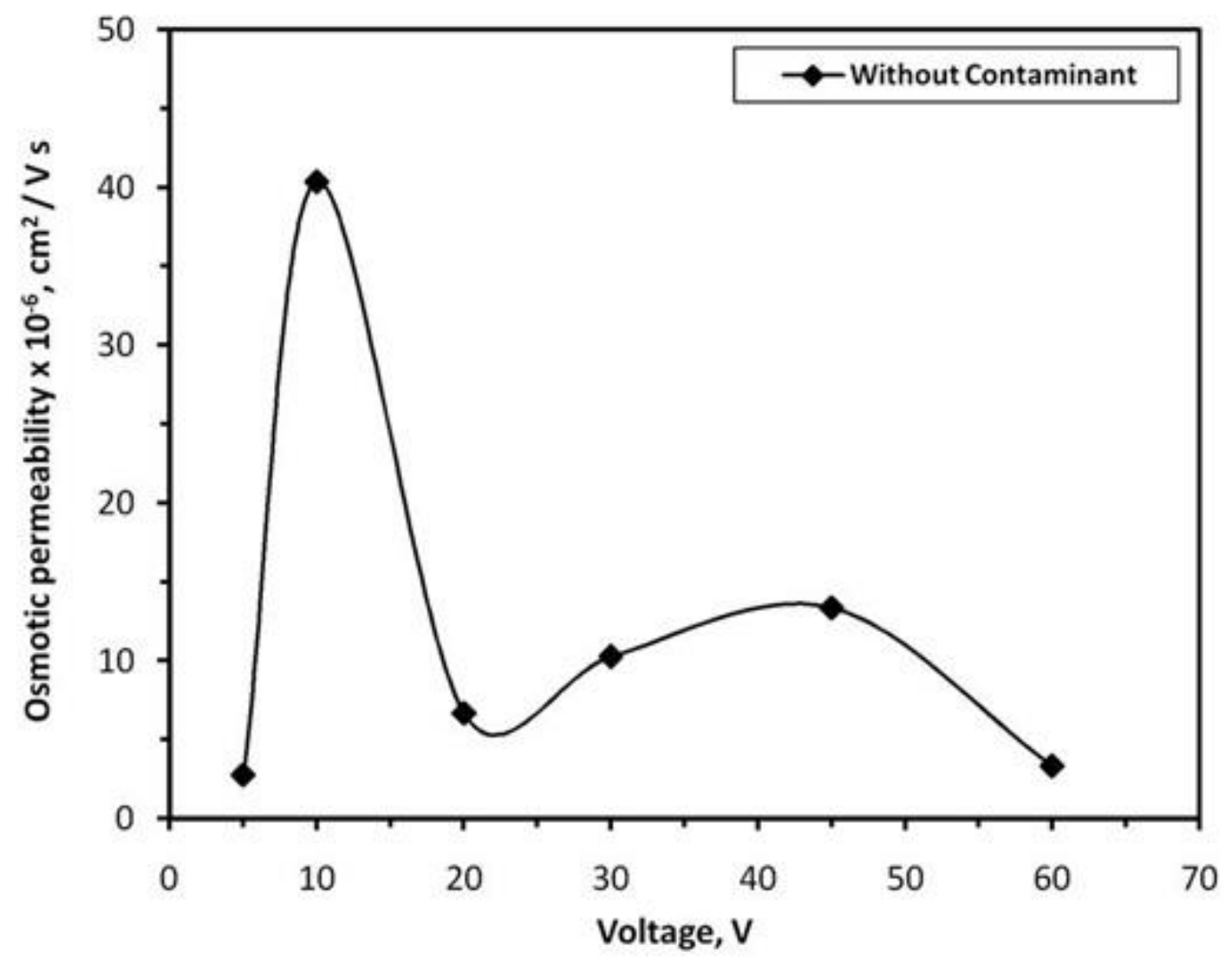

Fig. 4. Electro-osmotic permeability in uncontaminated soil

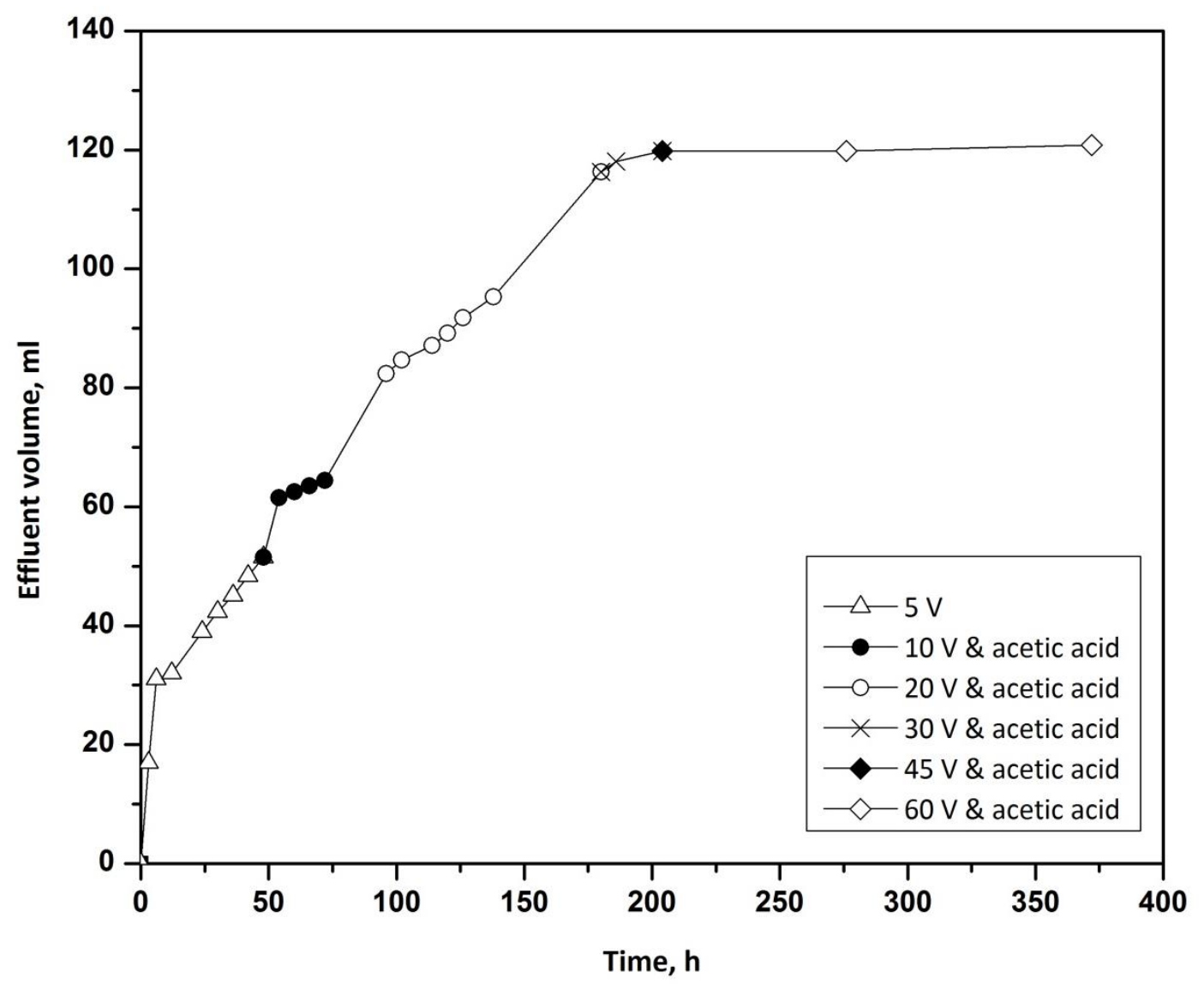

Fig. 5. Electrokinetic flow through soil contaminated with nickel ions 
The range of electro osmotic permeability with nickel as contaminant in red earth is 0 to $3.55 \times 10^{-5} \mathrm{~cm}^{2} / \mathrm{Vs}$ as shown in Fig. 7. A maximum electro osmotic permeability of $3.55 \times 10^{-5} \mathrm{~cm} 2 / \mathrm{V}$ s was observed at 5volts. Induction of further voltage (10 V) reduces the electro osmotic permeability by almost 3 times and further increments in the voltage $(20,30,45,60 \mathrm{~V})$ gradually reduce the electro osmotic permeability and minimum value $\left(0 \mathrm{~cm}^{2} / \mathrm{Vs}\right)$ at $60 \mathrm{~V}$. The electro osmotic permeability of soil with nickel as contaminant is observed to be maximum value of $3.55 \times 10^{-5} \mathrm{~cm}^{2} / \mathrm{V} \mathrm{s}$, even with a low applied voltage of $0.167 \mathrm{~V} / \mathrm{cm}$ only.

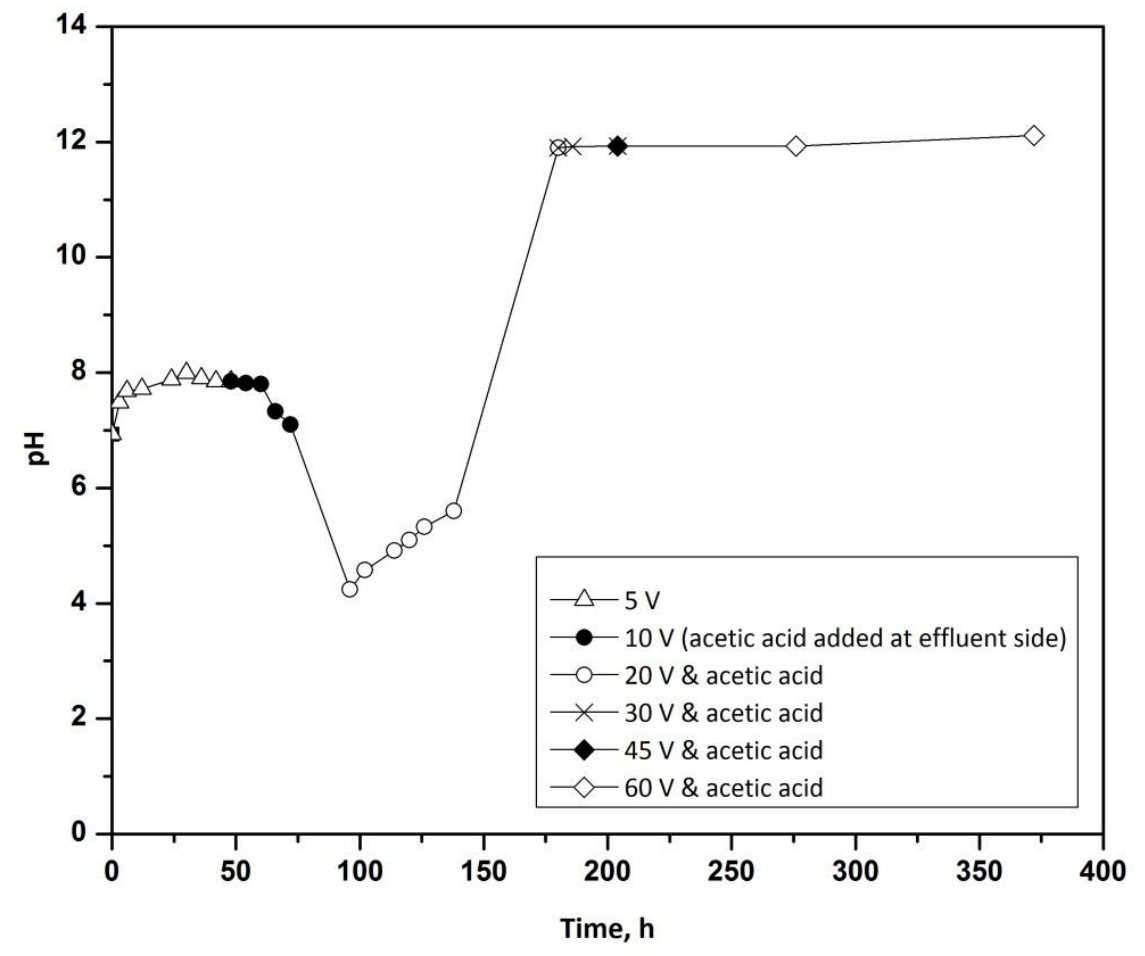

Fig. 6. Variation of $\mathrm{pH}$ of the effluent from soil contaminated with nickel ions

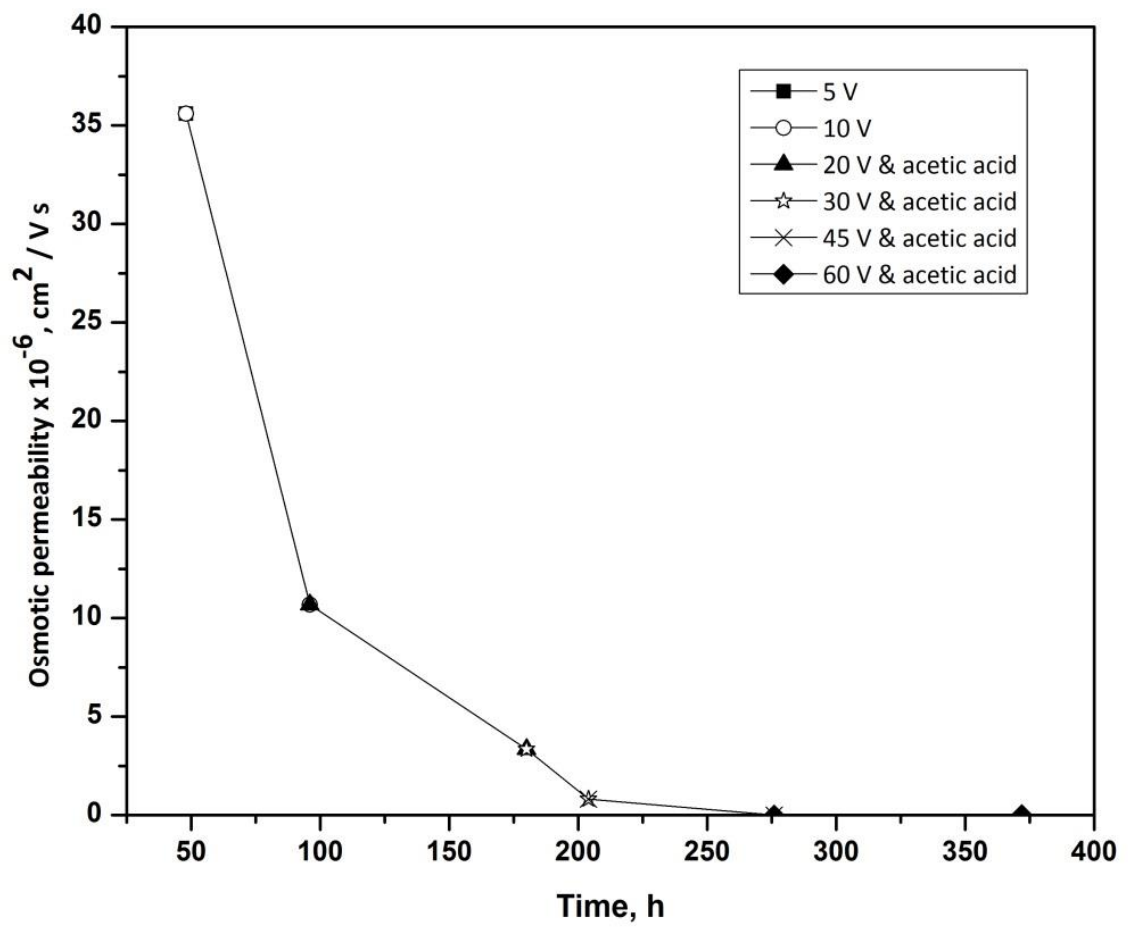

Fig.7. Electro-osmotic permeability of soil contaminated with nickel ions 
Effect of cadmium ions on the osmotic flow through the soil

Application of voltage $(5 \mathrm{~V})$ induced the flow initially with gradual reduction along with time as shown in Fig. 8. Increase of voltage $(10 \mathrm{~V})$ doesn't compliment the flow even with addition of acetic acid as shown in Fig. 8, may be due to consequent precipitation of cadmium hydroxide, further increase in voltage doesn't improve the flow, but with addition of acetic acid the flow enhancement was significant. With increase in $\mathrm{pH}(12.18)$ the flow reduces in Fig. 9, even with further applications of prolonged voltages.

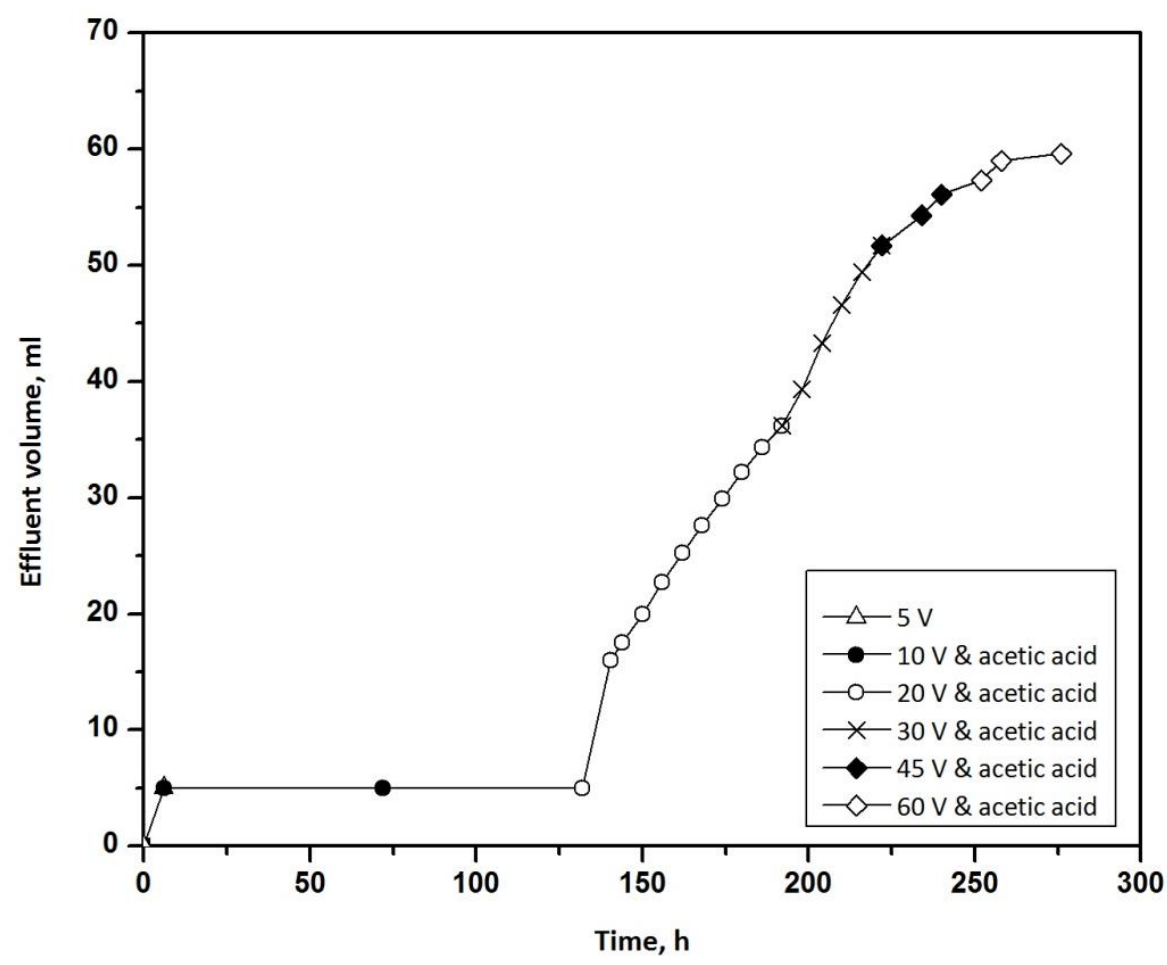

Fig. 8. Electrokinetic flow through soil contaminated with cadmium ions

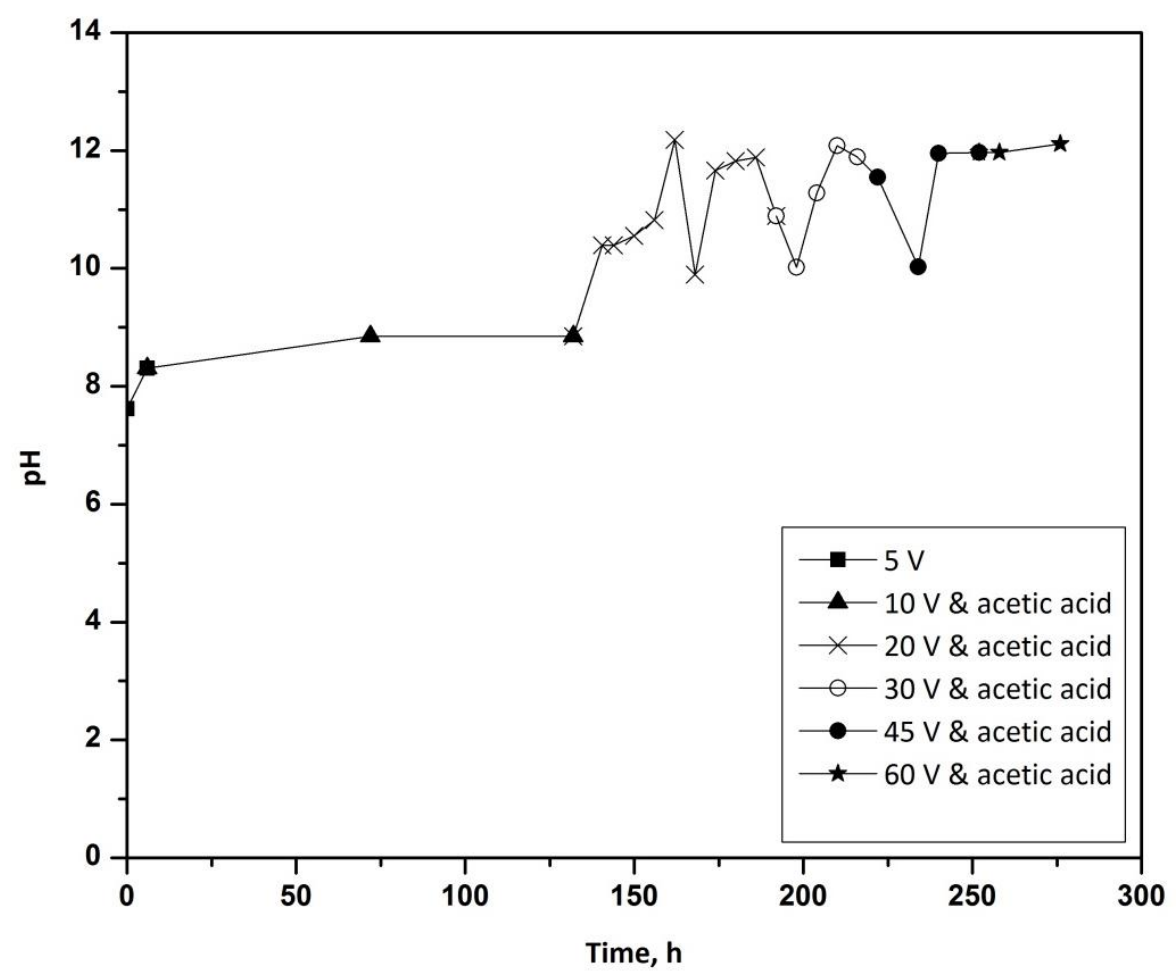

Fig. 9. Variation of $\mathrm{pH}$ of the effluent from soil contaminated with cadmium ions 
The electro osmotic permeability of red earth with cadmium as contaminant is in the range of 0 to $2.7 \times 10^{-5} \mathrm{~cm}^{2} / \mathrm{V} \mathrm{s}$, Fig. 10 . The electro-osmotic permeability was $2.7 \times 10^{-5} \mathrm{~cm}^{2} / \mathrm{V} \mathrm{s}$ at a voltage of $5 \mathrm{~V}$ with a maximum flow rate. May be due to the precipitation of cadmium hydroxide at cathode the electro osmotic permeability and rate of flow were zero at $10 \mathrm{~V}$.

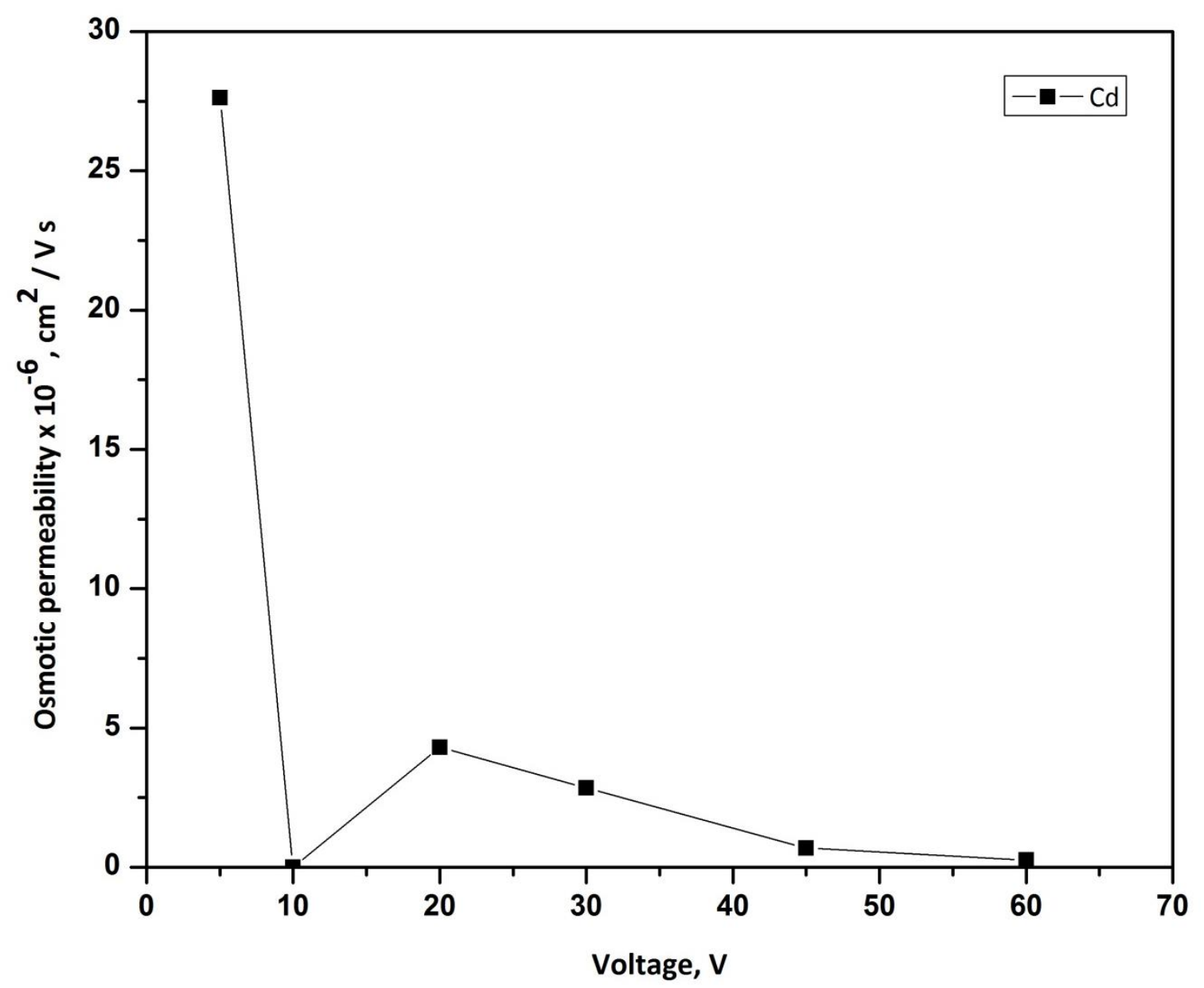

Fig. 10. Electro-osmotic permeability of soil contaminated with cadmium ions

A marginal increase was observed with increase in voltage to $20 \mathrm{~V}$. Further increase in voltage with acetic acid resulted in gradual decrease in electro osmotic permeability. Presence of cadmium as contaminant doesn't increase the electro osmotic permeability. Maximum electro osmotic permeability $\left(2.7 \times 10^{-5} \mathrm{~cm}^{2} / \mathrm{V} \mathrm{s}\right)$ is observed at $0.167 \mathrm{~V} / \mathrm{cm}$.

Effect of Ferric lons on the osmotic flow through the Soil

A sudden initial flow was observed on application of 5 volts initially and it subsequent reduction along with time as in Fig. 11. No change was observed when the voltage was increased to $10 \mathrm{~V}$ along with addition of acetic acid. Increase in the flow was seen on addition of acetic acid at higher voltage of $20 \mathrm{~V}$, subsequent increase in voltage to $30 \mathrm{~V}$ doesn't enhance the flow (Fig. 11), may be due to the low ionic mobility of iron. During the whole process the $\mathrm{pH}$ doesn't vary substantially as shown in Fig. 12. 


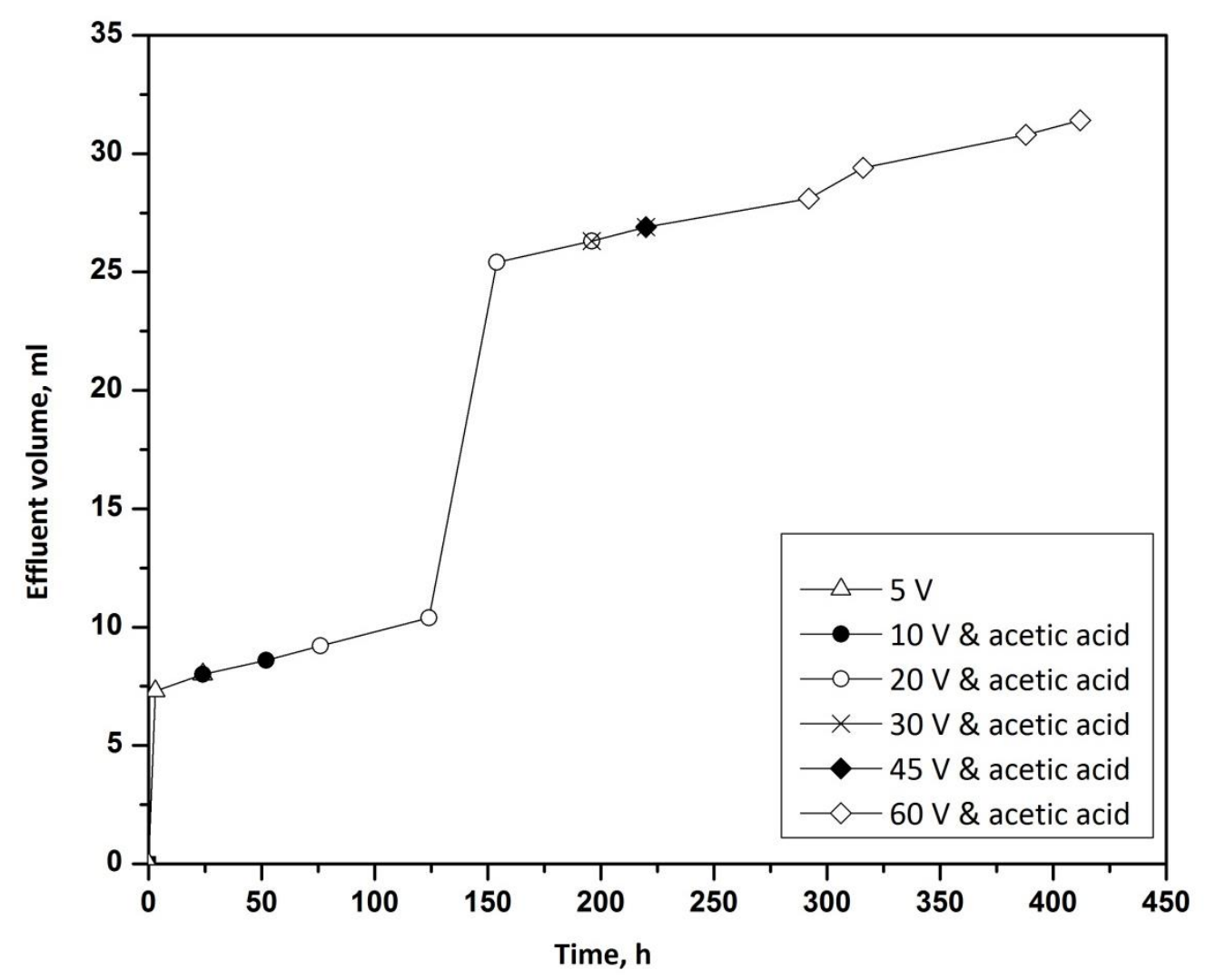

Fig. 11. Electrokinetic flow through soil contaminated with ferric ions

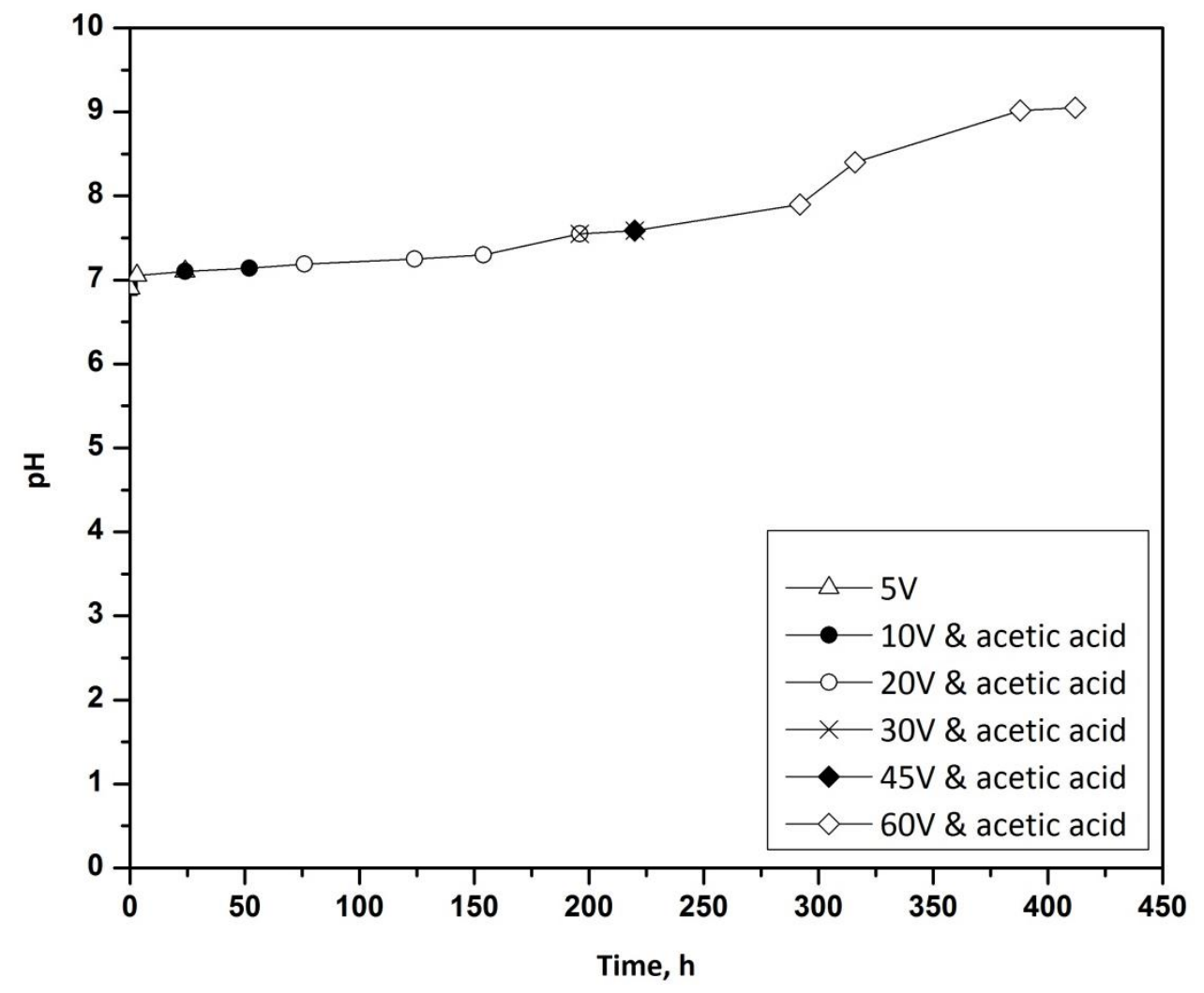

Fig. 12. Variation of $\mathrm{pH}$ of the effluent from soil contaminated with ferric ions 
The range of electro osmotic permeability of red earth with iron as contaminant is in the range of $6 \times 10^{-7}$ to $1.1 \times 10^{-5} \mathrm{~cm}^{2} / \mathrm{Vs}$, as shown in Fig. 13. A maximum electro osmotic permeability of $1.1 \times 10^{-5} \mathrm{~cm}^{2} / \mathrm{Vs}$ was monitored at 5 volt as shown in Fig. 13. And a sudden decrease of electro osmotic permeability was observed at an applied voltage of $10 \mathrm{~V}$. It subsequently increased with higher voltage of $20 \mathrm{~V}$. The electro osmotic permeability remained at constant rate with further increase in the voltages as shown in Fig. 13. The maximum electro osmotic permeability of $1 \times 10^{-5} \mathrm{~cm}^{2} / \mathrm{V}$ s is observed at $0.167 \mathrm{~V} / \mathrm{cm}$.

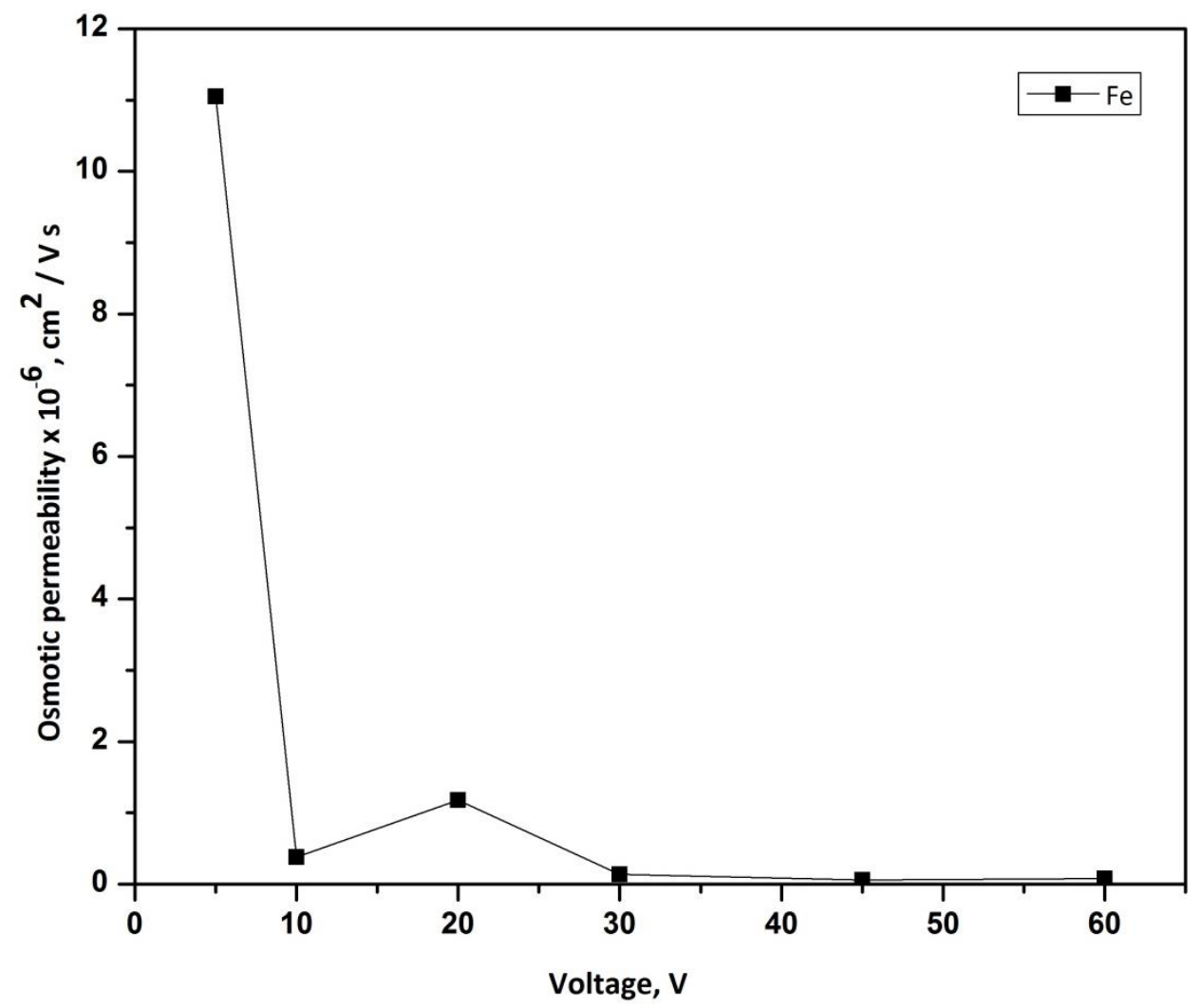

Fig.13. Electro-osmotic permeability of soil contaminated with ferric ions

\section{Electrokinetic extraction of metal ions}

The extent of removal of a metal ion from any soil depends on the mobility of the ion and its affinity for the soil clay. The lower is the ionic mobility and the higher is the affinity, the lower is its removal from the soil. The removal also depends upon the solubility product of the species and the $\mathrm{pH}$ of the system. As the solubility product at any $\mathrm{pH}$ increases their solubility product, the ion is precipitated and hence not removed. The effectiveness of acetic acid to lower the $\mathrm{pH}$ and enhance their removal as well as the efficiency of EDTA solutions to enhance desorption of the ion from the soil and hence to increase its removal However during each of these phases the processes might not have been completed. Only the removal trends with different fluids such as water, acetic acid and EDTA solution have been studied. With each fluid the applied voltage is varied. Also the percent removal of the species with respect to increase in osmotic flow has been compared.

How the selected contaminants respond to the removal by electrokinetics with respect to osmotic flow generated at different acidic and alkaline conditions existing during Electrokinetic process are discussed in detail. 


\section{Removal of nickel from red earth}

It can be seen from Fig. 14 that the amount of removed $\mathrm{Ni}$ is almost proportional to the quantity of the flow generated during different phases of electrokinetic process while passing acetic acid and water. This shows that the removal is essentially due to osmotic flow. However, prolonged application of $10 \mathrm{~V}$, while increasing the flow does not proportionally enhance the removal of $\mathrm{Ni}$. This might be due to precipitation of $\mathrm{Ni}$ at enhanced $\mathrm{pH}$. Increasing the voltage and passing acetic acid greatly help to remove the $\mathrm{Ni}$ contamination. This confirms that $\mathrm{Ni}$ is actually precipitated and by passing acetic the rate of removal of $\mathrm{Ni}$ is greater than the increased flow due to sudden dissolution of precipitated $\mathrm{Ni}$. Thus passing of acetic acid not only reduces $\mathrm{pH}$ at cathode but also enhances the electro-osmotic flow as well as desorption of $\mathrm{Ni}$ from the surface of clay particles. With a small increase in voltage from $10 \mathrm{~V}$ to $20 \mathrm{~V}$, brings about maximum removal of about $35 \%$.

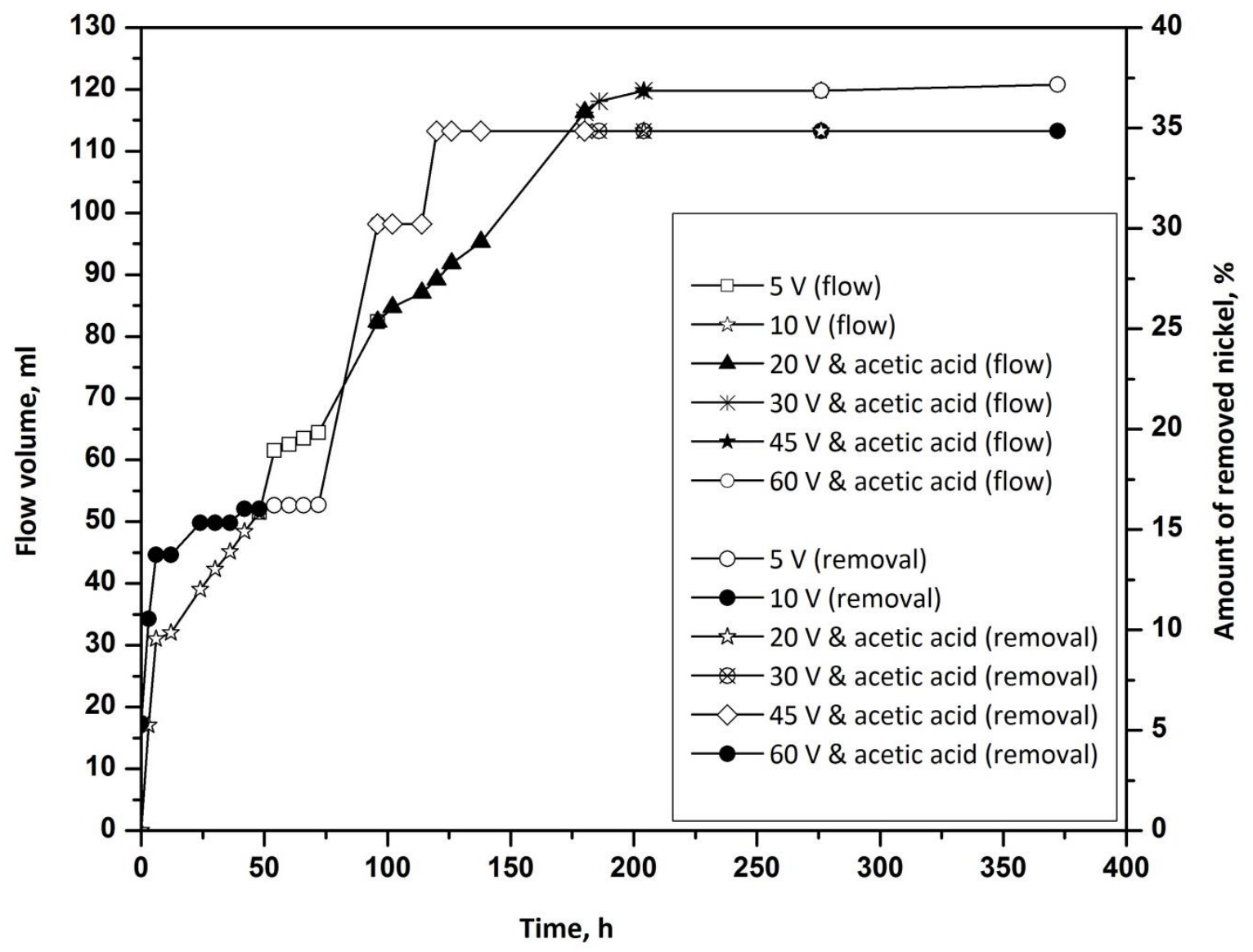

Fig. 14. Removal trends of nickel ions from soil by electrokinetic process

As seen from Fig. 14 further increase in voltage (20 - $30 \mathrm{~V})$ increases osmotic flow and amount of removed $\mathrm{Cd}$ is also proportional to electro osmotic flow.

Further, prolonged application of voltage beyond $30 \mathrm{~V}$ the rate of flow decreases and tends to be more or less constant as result of increasing $\mathrm{pH}$ at the cathode. Thus, prolonged application of voltage beyond $30 \mathrm{v}$ is not beneficial in extraction of nickel form red earth. 


\section{Removal of cadmium from Red Earth}

Removal of $\mathrm{Cd}$ from red earth is compared with the quantity of flow that is generated at different voltages and by passing water or dilute acetic acid. It can be seen from Fig. 15 that the amount of removed $\mathrm{Cd}$ is almost directly proportional to the quantity of flow generated. The variations in the rate of flow at different conditions that exist during the electrokinetic extraction are discussed earlier. There is no phase during which the removal of $\mathrm{Cd}$ is greater than the rate of flow. This indicates that either $\mathrm{Cd}$ is not precipitated or the precipitated $\mathrm{Cd}$ is not dissolved at $\mathrm{pH}$ obtained by passing acetic acid. This might be due to the low solubility product of cadmium hydroxide. This indicates that desorbing of $\mathrm{Cd}$ from soil is not a major limitation for removal by electrokinetics. During different conditions of removal the maximum removal of $\mathrm{Cd}$ is about $16 \%$. The amount of removed $\mathrm{Cd}$ can be enhanced if the rate of flow is maintained for longer periods. The osmotic flow itself is greatly increased by increasing the applied voltage to $20 \mathrm{~V}$ along with acetic acid. Increasing the applied voltage beyond $30 \mathrm{~V}$ is not beneficial in enhancing the rate flow. Thus, for enhance removal of cadmium passing of about $20 \mathrm{~V}$ for longer periods is advisable.

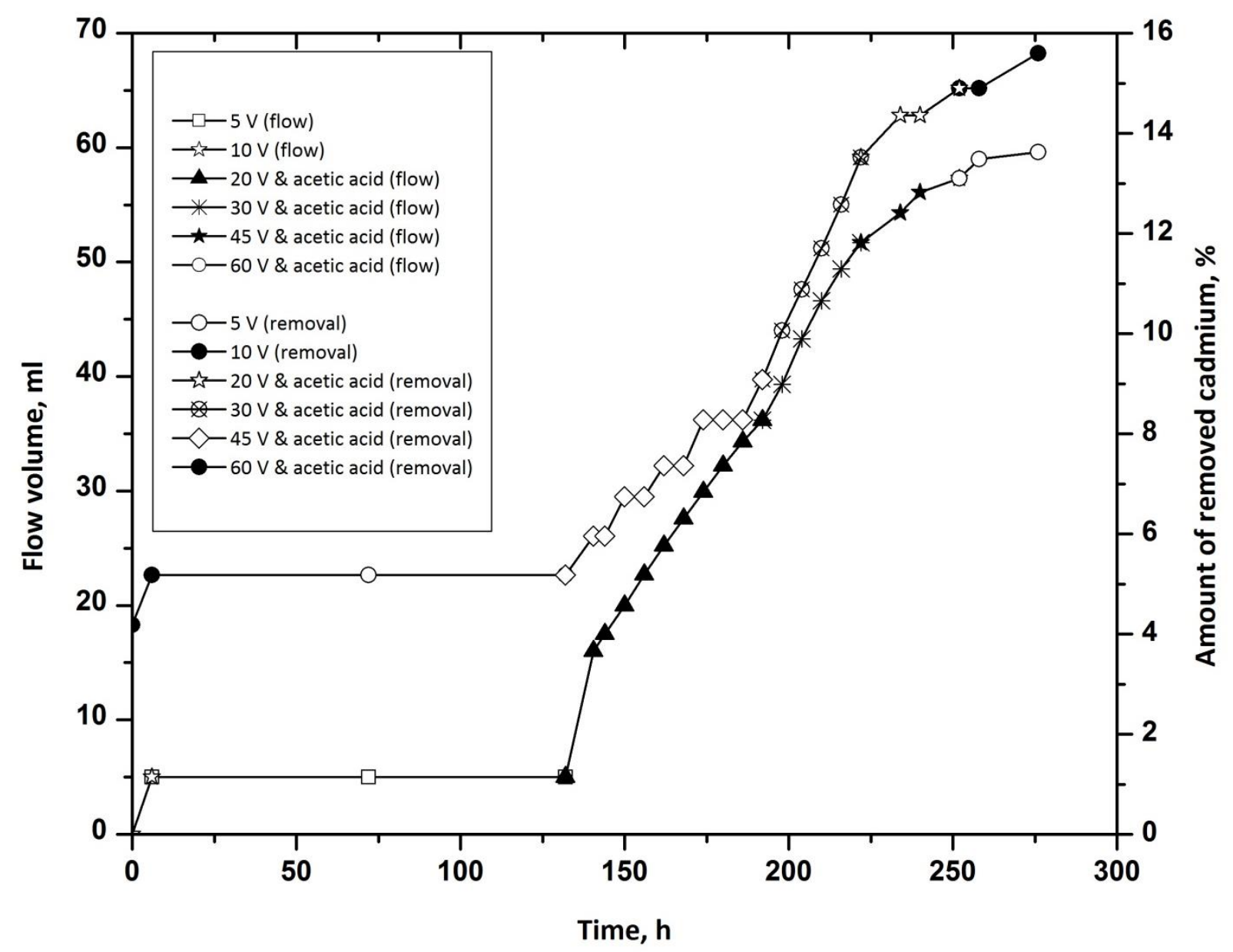

Fig. 15. Removal trends of cadmium ions from soil by electrokinetic process

\section{Removal of iron from Red Earth}

Percent removal of iron compared to the quantity of flow generated is not proportional at different voltages applied as well as passing of acetic acid solution and water during the electrokinetic extraction process as seen from Fig. 16 due to immediate precipitation as its hydroxide as well as the ion being strongly adsorbed to the clay particle. The solubility product of 
iron hydroxide is very low and hence is not dissolved and removed. Also, Fe might not have been removed due to its strong adsorption to the clay.

However, with increase in voltage to $60 \mathrm{~V}$ i.e., at $2 \mathrm{mV} / \mathrm{cm}$ it is observed that enhanced voltage desorbs the ions from clay surface and increase in \% removal of the contaminant. Thus, increase in voltage for longer durations might help to enhance its removal. However this method is not very effective for decontamination of iron from soil.

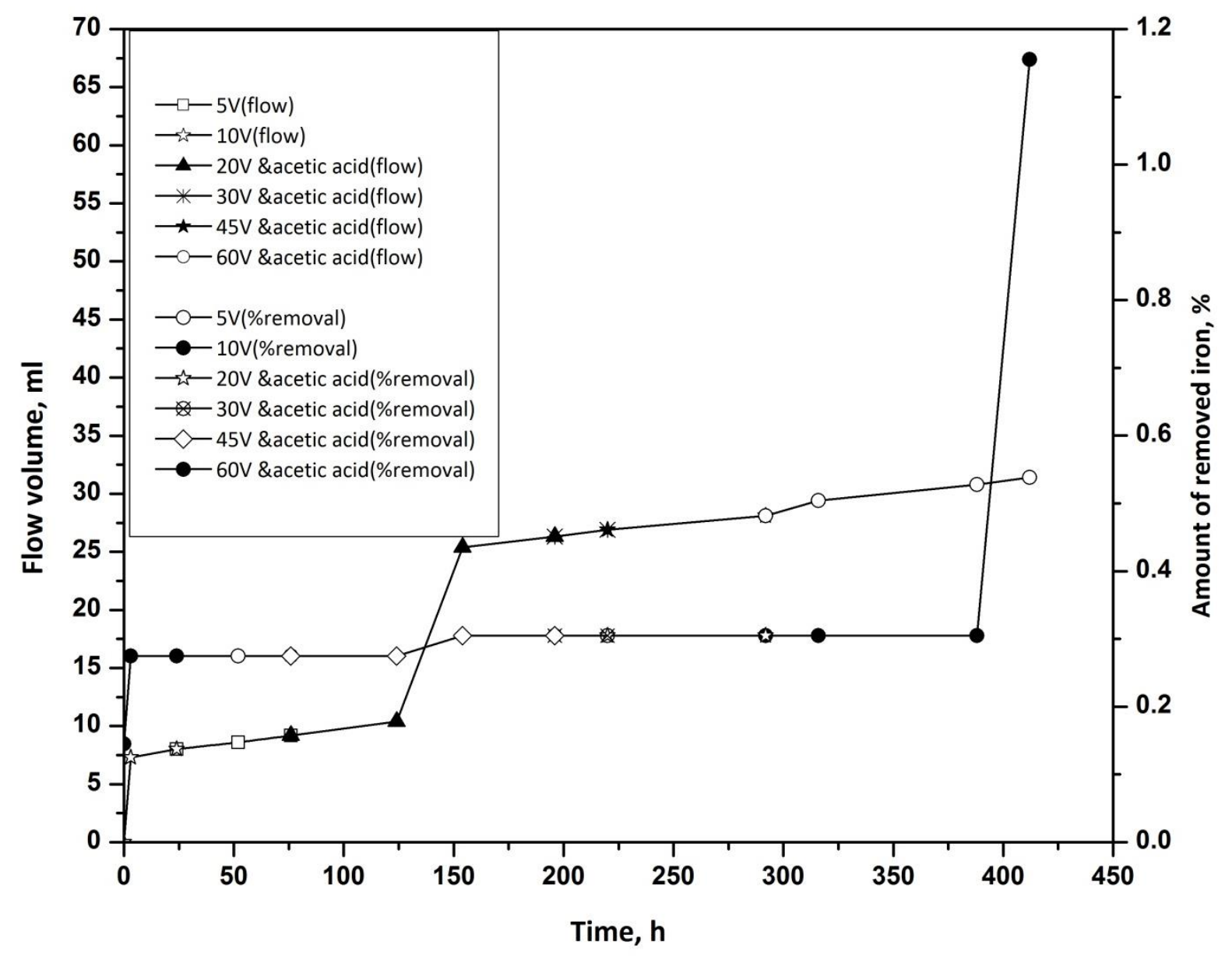

Fig. 16. Removal trends of ferric ions from soil by electrokinetic process

\section{Conclusions}

1. Osmotic permeability of soil is not significantly affected by the presence of ionic metal contaminants. The variation of osmotic permeability with different contaminants is in the order of Soil without contaminant $>\mathbf{N i}>\mathbf{C d}>\mathrm{Fe}$.

2. The rate of flow increases it is not proportional to the applied voltage. Presence of Fe reduces the electro osmotic permeability. The maximum osmotic permeability is obtained $0.167 \mathrm{~m} \mathrm{~V} / \mathrm{s}$. Presence of ionic contaminants reduces the applied voltage required to induce maximum osmotic permeability, though the maximum osmotic permeability induced itself doesn't increase. Passing of acetic acid doesn't enhance the electro osmotic permeability though the $\mathrm{pH}$ of the system is controlled.

3. The increase in $\mathrm{pH}$ with application of voltage across the contaminated soil increases with $\mathrm{Ni}$ and $\mathrm{Cd}$ as the contaminants are significantly more.

4. The amount of removed $\mathrm{Ni}$ is generally proportional to the osmotic flow but shows more sensitivity to the $\mathrm{pH}$ of the system than to the osmotic flow in case of Nickel. 
5. The amount of removed $\mathrm{Cd}$ contaminant is almost proportional to the osmotic flow generated in case of cadmium.

6. The amount of removed Fe is not proportional to the quantity of osmotic flow generated either by adsorption of the contaminant or if the removed contaminant is precipitated.

7. The higher is the solubility product and lower the affinity of the contaminant the higher is the decontamination of ionic metal contaminants..

\section{References}

[1] A. N. Alshawabkeh, Y. B. Acar, J. Environ. Sci. Heal. A 27 (1992) 1835-1861.

[2] A. T. Yeung, C. Hsu, R. M. Menon, J. Geotech. Eng. ASCE 122 (1996), 666-673.

[3] K. R. Reddy, U. S. Parupudi, S. N. Devulapalli, C. Y. Xu, J. of Haz. Mat. 55 (1997) 135-158.

[4] R. Lageman, W. Pool, G. A. Seffinga, Chem. and Ind. 18 (1989) 585-590.

[5] Y. B. Acar, A. N. Alshawabkeh, R. J. Gale, J. Waste Man. 13 (1993) 141-151.

[6] J. Hamed, Y. B. Acar, R. J. Gale, J. Geotech. Eng. ASCE 117 (1991) 241-271.

[7] P. C. Renaud, R. F. Probstein, J. PhysicoChem. Hydrodyn. 9 (1987) 345-360.

[8] Y. B. Acar, J. Hamed, A. Alshawabkeh, R. Gale, Geotechnique ICE, 44 (1994) 239- 254.

[9] T. Rødsand, B. Acar Yalcin, B. Gijs, Publikasjon-Norges Geotekniske Institute 195 (1996) 1518-1535.

(C) 2015 by the authors; licensee IAPC, Zagreb, Croatia. This article is an open-access article distributed under the terms and conditions of the Creative Commons Attribution license (http://creativecommons.org/licenses/by/3.0/) (cc) EY 